\title{
VERBAL PREFIXATION IN GERMAN CHILD AND ADULT LANGUAGE
}

\author{
HEIKE BEHRENS
}

\begin{abstract}
Previous research has demonstrated that children pick up even small differences in the lexicalization patterns of closely related languages quickly and successfully. This study examines verbal prefixation in German child and adult language, using a particularly detailed case study. The data show that the child starts to produce prefixed verbs and prepositional phrases within a few months. More crucially, the child's speech gets attuned to the precise frequency distribution of these constructions in the input. These findings support theories of linguistic relativity which emphasize the importance of the conventionality in language use for language processing and acquisition. A look at the input language reveals that the adults use hundreds of lexical items per hour which provide information about the use of verbal prefixation. Also, input frequencies did not change over time. This suggests that the structural properties of a given language are very stable, and help the child to become a proficient speaker.
\end{abstract}

Verbal prefixes play an important role in Germanic languages, and consequently in their acquisition. In terms of semantics, German represents a socalled satellite-verb language (Talmy 1985) with a division of labour between verb and prefix: the verb roots tend to encode manner information (e.g., manner-of-motion like scurry or jump), whereas the verbal prefixes encode directional, locational or aspectual information (jump up, fall down).

From a syntactic perspective, German has two types of verbal prefixes: separable and inseparable ones. I will refer to the first as "particle verbs" and to the latter as "prefix verbs". Prefix verbs resemble English ones like er-innern ('re-mind') or ent-spannen ('un-wind'). Particle verbs, however, differ from English in that the particle precedes the verb in the unseparated forms like infinitives or past participles (weg-schwimmen 'swim away' or wegge-schwommen 'swum away'). But finite forms in main clauses are separated, following the general rules of German verb placement (1). In subordinate clauses, however, particle verbs are not separated and appear sentence finally (2). 
(1) Er schwamm vor den grossen Haien weg

he swam from the big sharks away

'He swam away from the big sharks.'

(2) Er hatte so grosse Angst, dass er vor den Haien wegschwamm he had such big fear, that he from the sharks away.swam

'He was so afraid that he swam away from the sharks.'

In contrast to most inseparable prefixes, particles are independent lexical units. They can occur in isolation, and in many cases they are identical to prepositions (for a more detailed survey of the properties of German and Dutch particle verbs see Blom-Booij 2003).

This paper focusses on the acquisition of particle verbs, a much larger and more productive group than the prefix verbs. Their syntactic separability makes German particle verbs a complex phenomenon to acquire: First, children have to learn that these particle verb combinations are lexical units across different syntactic conditions. Second, they have to identify the conditions under which they are separated. There are several studies which focussed on the syntactic competence of children, i.e., when and how they become able to use particle verbs in accordance with adult-like syntactic representations. These studies emphasize that the basic syntactic properties of language are acquired early (e.g., Bennis et al. 1995). But the emphasis of this paper is not on the syntactic properties of particle verb constructions as such, but on the processes by which children get attuned to the distribution or use of particle verb constructions as opposed to other syntactic alternatives like prepositional phrases. This approach fits in with recent developments in language acquisition theory and typological research which emphasize the role of language use for shaping children's grammar and adults' preferences for encoding events (see below).

\section{Individual and intra-typological variation in the acquisition of particle verbs}

Previous research in several Germanic languages has shown that particle verbs do not provide an acquisition problem. They are not delayed because children would first focus on simplex verbs and acquire the more complex particle verbs only later (e.g., Behrens 1998). It is likely that the acquisition of particle verbs is facilitated by the previous and frequent use of verbal particles in isolation. Typically, children learning Germanic languages use particles like $u p$ in a verb-like fashion (to mean 'I want up'), before they acquire true lexical 
verbs (Clark 1993). Likewise, particle verbs are often acquired earlier than semantically corresponding simplex verbs. For instance, children are more likely to use particle verbs like auf-machen ('to make open', i.e., 'to open') and $z u$-machen ('to make close', i.e., 'to close') than the equivalent öffnen ('to open') or schliessen ('to close') (Behrens 1998). This preference for particle verbs indicates that morphological and syntactic complexity do not form obstacles for language acquisition. Instead, from a functional perspective, both the particle and the verb root carry meaning, and their compositionality may simplify the identification of their semantics. Moreover, from a morphological perspective, particle verbs may facilitate acquisition because children can build up a rich repertoire of particle verbs with just a few verb roots. This reduces the task of learning paradigms of verb inflection. In sum, it is possible that the child prefers the particle verb variant because it represents a semantically transparent combination of well-mastered verbal particles and highly frequent and semantically light verbs (like make or do).

But despite children's ease in acquiring particle verbs, previous crosslinguistic research demonstrated that there are distributional differences even between very closely related languages: Ragnarsdóttir-Strömqvist (1997) compared child and adult data from North-Germanic languages and found more prepositional phrases than particle verbs in Icelandic, but more particle verbs than prepositional phrases in Swedish. Regarding West-Germanic child language Behrens (1998) found that German children use more particle verbs than Dutch or English children, but that Dutch and English children use more prepositional phrases than German children. The difference between German and Dutch is quite surprising because they have identical structural properties. That is, Dutch particle verbs are as simple or difficult as German ones. Thus, the difference in the proportion of particles in child language supposedly lies outside the purely syntactic domain. From a usage-based perspective (Tomasello 2000b), the child could simply use these particle verbs because adults show this preference, too. To date, there are hardly any reliable linguistic data on the distribution of these structures in the input. In this paper I will try to fill this void for German child and adult language, and to answer questions regarding the nature of the input children get over time.

\section{Research questions}

Are children sensitive to the distributional preferences found in the adult language or do they over- or underuse certain structures, and if so, when? 
Are developmental changes influenced by changes in the input language such that adults adopt their speaking style to the growing linguistic capacities of the child? To investigate these issues, I will first compare the use of particle verbs between German child and adult language across language development.

The next question to ask is what causes children's early proficiency with particle verbs. If children initially prefer them because of their semantic and morphological transparency, they should be relatively more frequent in the child than in the input data. In addition, early particle verbs should be restricted to relatively fewer verb roots than later on. Finally, I will look at the speech production rate in adult and child language in order to address the issue of how the conventions of language use might influence the acquisition process.

\section{The database}

The analyses are based on data from a particularly detailed case study of a monolingual German boy called Leo. The data cover Leo's language development from the onset of the two-word stage at age 1;11 (age in years;months) up to age $4 ; 11$, when complex sentences were well established. Our so-called "High-Density-Developmental-Corpus" contains diary data as well as five onehour recordings per week between the ages of two and three, and a follow-up study of five hours a week once a month for another two years. That is, these acquisition data were sampled at a 5 to 10 times higher rate than usual for acquisition corpora. All recordings were made in the child's home setting. Between 2;0 and 3;6 one particular research assistant did one recording a week, the rest of the recordings were made by the parents. All recordings were transcribed according to the guidelines of the CHILDES-system (MacWhinney 2000).

\section{Coding categories}

There is a total of 383 one-hour recordings. The corpus size of the child data is almost half a million words $(\sim 496,000)$. The corpus of the adult input contains 1,354,000 words. All child data and a size-matched corpus of the adult data $(\sim 528,000$ words) were coded for part of speech, inflection, and lemma information. Regarding the parental speech, samples were taken from different intervals across the investigation period because it is conceivable that 
parents adapt their speaking style to the growing linguistic capacities of the child. For the domain studied here, only the part of speech and the lemma information are relevant:

(3) PART-OF-SPEECH CODING

(a) simplex main verb (without particle) Excluded are modal verbs, auxiliaries, and copula tokens.

(b) unseparated particle verbs (e.g., aufmachen 'open.make')

(c) separated particle verbs (e.g., er macht es auf 'he makes it open' = 'opens it')

(d) verbal particles without lexical main verb, when used in a verb-like fashion (e.g., hoch! 'up!' ; muss ab 'must off') ${ }^{1}$

(e) prepositions heading an NP or PRO

In addition, the codes provide lemma information and relate all inflected forms to their citation form. In the case of verbal prefixation, special characters mark whether it is an inseparable prefix verb or a separable particle verb. The codes also indicate whether particle verbs occurred in separated or unseparated format. A set of control commands was run to check the consistency of coding.

\section{Analyses}

\subsection{Structural diversity and development}

In this section I will look at the distribution of satellite and verb tokens in the child and the adult data. The first analysis compares the proportion of simplex, particle, and prefix verbs in the dense database to the data from German, Dutch and English child language presented in Behrens (1998). The second analysis takes a closer look at the child's development, as well as at

1 Particles outside of particle verb constructions pose certain coding problems because they also occur in other constructions: when they occur with copulas, they function as sentence adverbials and were coded as adverb, not particle (e.g., ist weg 'is away'). When they occur with modal verbs, however, they were coded as particle because they tend to represent an elliptical main verb (e.g., wir müssen weg 'we must away' means something like 'we must go away'). From this it follows that combinations of "copula + adverb" or "modal verb + particle" were not coded as particle verbs. Only combinations of lexical verbs and particles were coded as particle verbs. 
the distributional patterns in the input language over time. The aim is to see when the child's system stabilizes, and to provide information about the stability or variability of the input across development. Finally, the proportion of particle verbs in the adult and child data is compared to test whether particle verbs offer a more salient perspective for the child.

As pointed out above, the proportions in the use of particle verbs varied between German, Dutch, and English children (Behrens 1998). The first question to ask is whether Leo behaves like the other German children, or whether he shows a different patterning, due to either different individual preferences (as is the case for the Dutch boy Niek), or due to the more reliable sample size. The second question to address is whether we see a similar distribution in the adult data, i.e., Leo's ambient language. Table 1 reproduces the data from Behrens $(1998,692)$ and adds the corresponding information for Leo and his input. The number of verb tokens includes all verbs which function as the main verb of an utterance (i.e., lexical verbs, copulas, and modal verbs).

Table 1

Percentage of particle and prefix verb tokens

\begin{tabular}{|l|l|l|r|r|c|c|}
\hline Language & Child & $\begin{array}{c}\text { Age studied } \\
\text { (years;months) }\end{array}$ & $\begin{array}{c}\mathrm{n}=\text { verb } \\
\text { tokens }\end{array}$ & $\begin{array}{c}\text { \% simplex } \\
\text { verbs }\end{array}$ & $\begin{array}{c}\text { \% particle } \\
\text { verbs }\end{array}$ & $\begin{array}{c}\% \text { prefix } \\
\text { verbs }\end{array}$ \\
\hline \hline English & Naomi & $1 ; 2-3 ; 8$ & 8545 & 89 & 11 & $<1$ \\
\hline & Adam & $2 ; 3-4 ; 0$ & 22958 & 89 & 11 & $<1$ \\
\hline \hline Dutch & Laura & $\begin{array}{l}1 ; 9-2 ; 1 \\
\text { and } 2 ; 9-2 ; 10\end{array}$ & 977 & 94 & 6 & $<1$ \\
\hline & Thomas & $2 ; 3-2 ; 11$ & 5404 & 88 & 11 & $<1$ \\
\hline & Hein & $2 ; 4-3 ; 1$ & 4851 & 89 & 10 & $<1$ \\
\hline & Niek & $2 ; 7-3 ; 11$ & 6082 & 81 & 18 & 1 \\
\hline \hline German & Julia & $1 ; 11-2 ; 5$ & 205 & 70 & 30 & 0 \\
\hline & Daniel & $2 ; 9-3 ; 6$ & 618 & 77 & 22 & $<1$ \\
\hline & Mathias & $2 ; 9-3 ; 6$ & 752 & 78 & 21 & 1 \\
\hline & Simone & $1 ; 9-4 ; 0$ & 13323 & 81 & 18 & 1 \\
\hline & Leo & $1 ; 11-4 ; 11$ & 69864 & 77 & 20 & 3 \\
\hline & Leo's input & sample & 85110 & 78 & 18 & 4 \\
\hline
\end{tabular}

It turns out that Leo and his adult conversation partners use a very similar proportion of particle verbs, and that they resemble all other German children (except Julia) quite closely, but show a different distribution from the Dutch and English children (except Niek). Both Leo and his caregivers use more inseparable prefix verbs than the other children in the sample. Inseparable prefix verbs tend to be semantically more abstract and tend to belong to a 
higher repertoire. Hence their higher proportion is probably due to the fact that the Leo-corpus includes data up to a later age and is therefore more likely to capture semantically and conceptually more advanced vocabulary. Also, the chance of sampling infrequent items increases with sample size.

It is noteworthy that within each language the distribution of these structures is the same regardless of the sample size (e.g., the Leo and input corpora are about 100 times larger than the Daniel and Mathias corpora). That is, the distributional properties seem to be fairly stable features of (spoken) language. The only exceptions are the data of Dutch Niek, who seems to be an outlier for Dutch in several respects (Wijnen-Bol 1994; Behrens 1998), as well as the data for Dutch Laura and German Julia. Their corpora, however, are not only small in size, but also cover mainly the very early stages of development. It is likely that the distribution differs in the early stages of language development, but that this difference levels out in the later stages.

\subsection{Overall comparison adult - child}

The following comparisons of Leo and his caregivers include the five categories listed in (1) above. However, the computation differs from that in Table 1 and Behrens (1998), where the count of simplex verbs included copulas and modal verbs when they were the main verb of a clause. But since copulas and modals do not form particle verbs, they are excluded here. This step reduces the number of simplex verbs compared to Table 1, but helps to provide a clearer picture of the proportion of verbal prefixation, because this analysis as well as the following ones includes only those simplex verb roots which in principle could combine with particles.

Table 2

Overall frequency of verbs and satellites (token frequency)

\begin{tabular}{|l|c|c|c|c|c|}
\cline { 2 - 4 } \multicolumn{1}{c|}{} & \multicolumn{3}{c|}{ LEXICAL VERBS } & \multirow{2}{*}{} & \multirow{2}{*}{ PARTICles } \\
\cline { 2 - 4 } \multicolumn{1}{c|}{} & $\begin{array}{c}\text { Simplex } \\
\text { Verbs }\end{array}$ & $\begin{array}{c}\text { Unseparated } \\
\text { Particle Verbs }\end{array}$ & $\begin{array}{c}\text { Separated } \\
\text { Particle Verbs }\end{array}$ & & \\
\hline Leo & 40.956 & 9.331 & 4.362 & 6.431 & 18.146 \\
\hline Input & 48.531 & 8.165 & 7.505 & 2.212 & 16.551 \\
\hline
\end{tabular}

Given that the adult sample is slightly larger than the child's, it turns out that the overall figures for simplex and particle verbs are quite compatible. The main difference regarding verb use is that the adults produce separated and unseparated particle verbs in even distribution, whereas Leo prefers the 
unseparated variant. Also, Leo produces many more isolated particles than the parents, and slightly more prepositional phrases. ${ }^{2}$

\subsection{The distribution of verbs and satellites in development}

In the next analyses, I take a developmental perspective and look at the distribution of verbs and satellites in Leo's speech and the input. Figure 1 shows the proportion of the five relevant categories in Leo's data across the three-year investigation period.

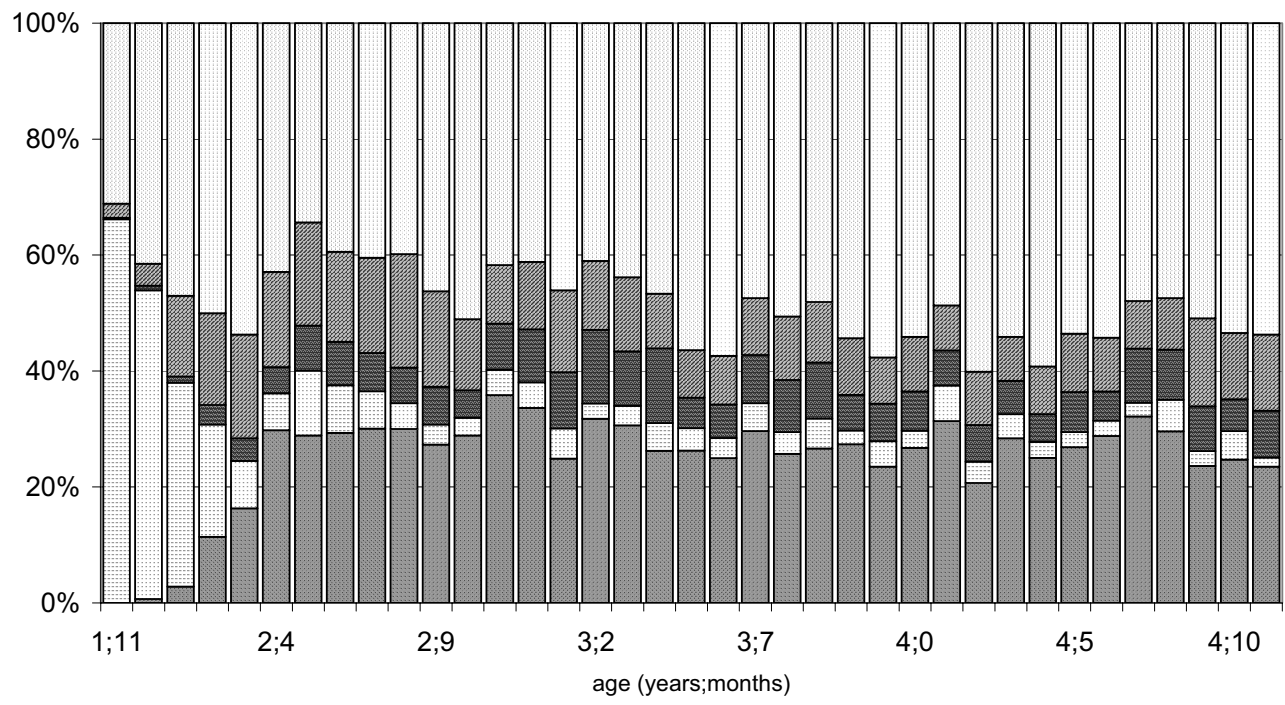

$\square$ Preposition $\square$ Particle 目Particle Verb: separated Particle Verb: unseparated $\square$ Simplex Verb

Fig. 1

Distributions of satellites and verbs: Leo

2 Compared to the other German children studied in Behrens (1998, 699), it is striking that Leo uses many more prepositions. Their ratio of PPs to main verbs was 1:13 whereas for Leo it is 1:4. In that, Leo's frequency of PPs resembles that of the Dutch and English children who used more prepositional phrases than particle verbs. However, Leo uses particle verbs at the same rate as the other German children. Thus, he does not use PPs in lieu of particle verbs, but in addition to them. Leo's frequent use of PPs may be due to his favourite topics train rides and constructing toy train landscapes or lego buildings. That is, he was constantly talking about trains going from here to there, or about putting things on/up/under something else. 
In the first two months, Leo's system basically consists of isolated verbal particles and simplex verbs. Satellites predominantly occur as isolated particles up to age $2 ; 1$. But already at age $2 ; 2$ particle verbs are used at their later level of frequency. First, they mainly occur in unseparated form. Separated particle verbs reach their later level of representation a few months later at age $2 ; 6$, and become as frequent as unseparated particle verbs by age 2;11. Also, prepositional phrases reach their later level of frequency at age $2 ; 4$. After age $2 ; 6$, the proportion of representation varies slightly, but there is no developmental trend towards the disappearance or increase of particular structures.

When we look at the adults (Figure 2) we see that the distribution of the respective structures stays stable over time. Only at 1;11 they use more isolated particles than later on. This shows that although Leo's caregivers are quite attuned to the child in these recording sessions (and beyond!), they do not simplify their grammar by using fewer verbs. Another difference is that the occurrence of separated and unseparated particle verbs is balanced in the adults whereas Leo takes almost a year for his unseparated verbs to catch up.

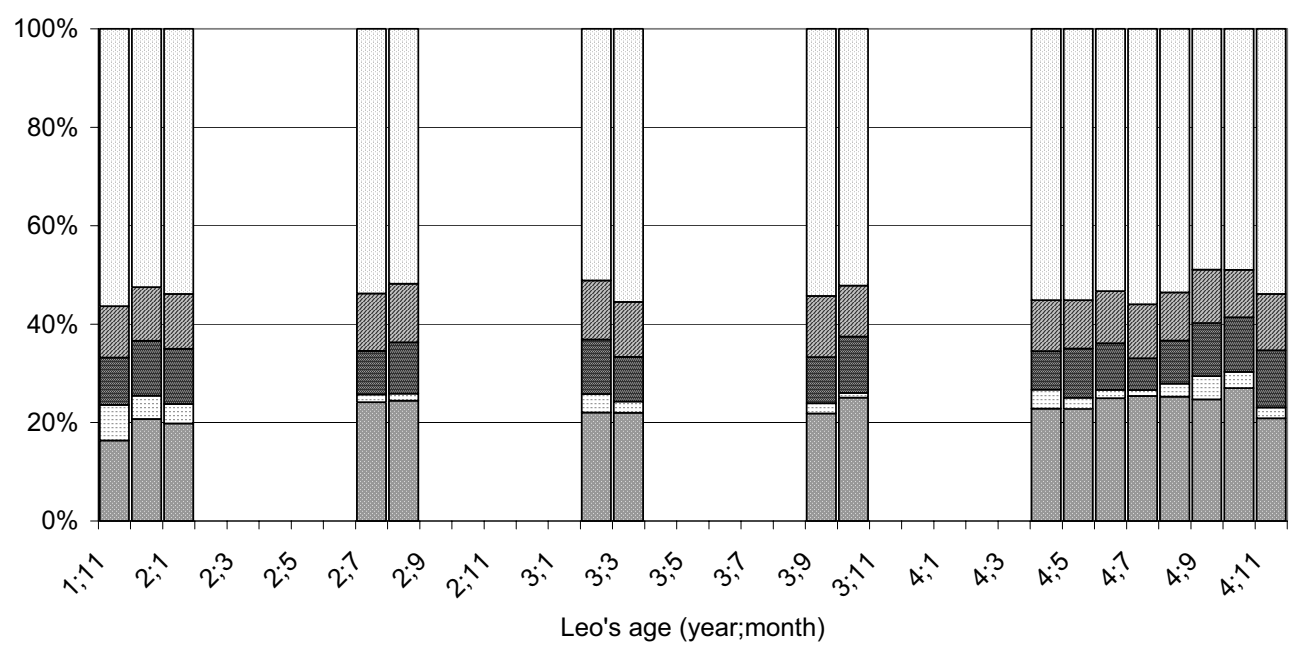

$\square$ Preposition $\square$ Particle $\mathbf{0}$ Particle Verb: separated 国Particle Verb: unseparated $\square$ Simplex Verb Fig. 2

Distributions of satellites and verbs in the input

The figures presented so far show that Leo does not have problems with particle verbs. But how does his use of particle verbs compare to that of the adults? Figure 3 depicts the percentage of particle verbs (based on the sum of simplex and particle verb tokens) across development. 


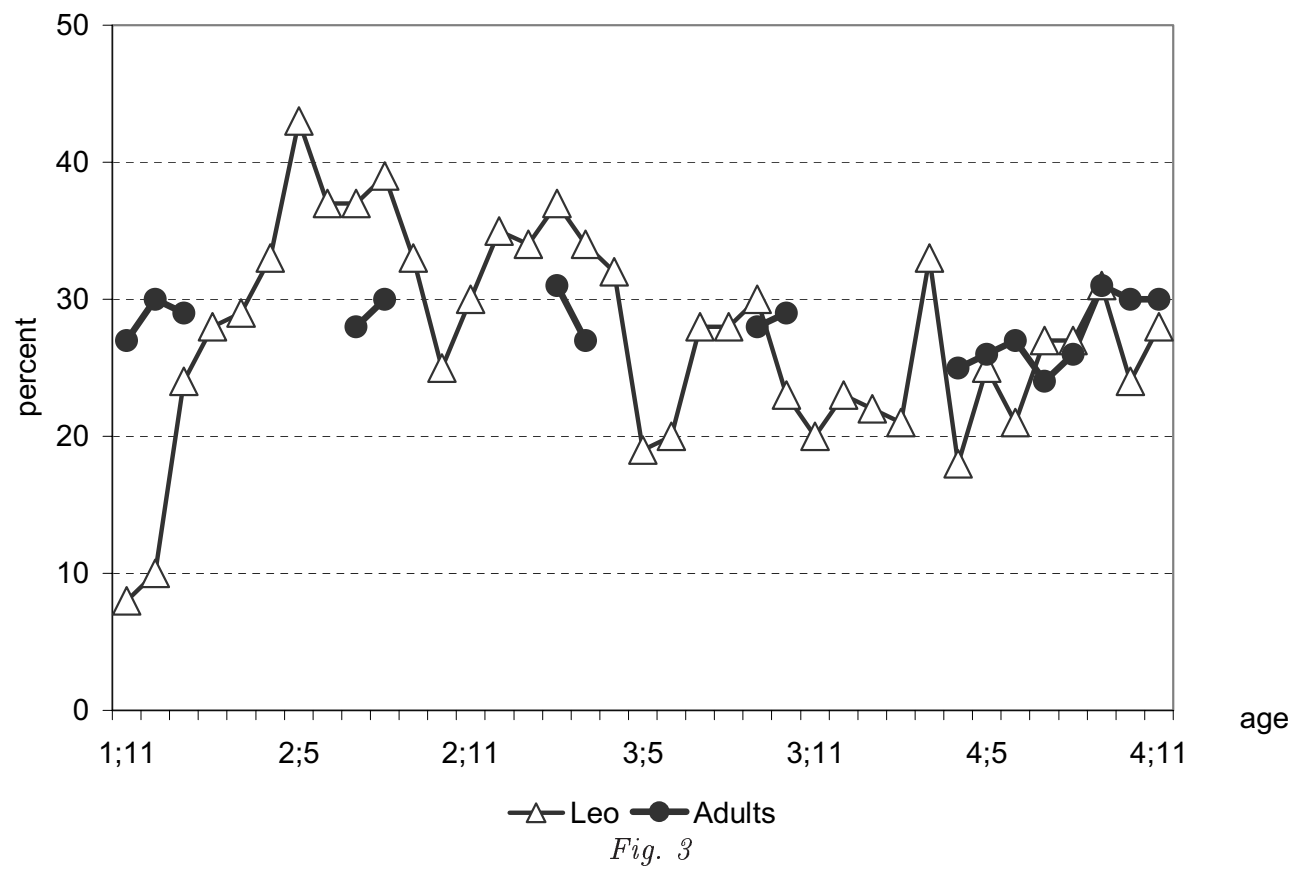

Percentage of particle verb tokens

In the adults, the rate of particle verbs varies only slightly between $24 \%$ and $31 \%$. In Leo's data, however, the proportion of particle verbs is more variable. First, it takes him some three months to reach the adult level. Subsequently, he overuses particle verb for about a year, and then underuses it. It is only in the last eight months of the observation period that his use of particle verbs approximates that of the adults.

A possible explanation for this initial over-use is that Leo acquires particle verb constructions so easily because he starts out by using a few verbs which he masters very well. If this hypothesis is correct, early particle verbs should be restricted to relatively fewer verb roots than later on. Likewise, the relative proportion of simplex, but lexically-specific verbs should increase over time. This hypothesis can be tested by looking at the lexical diversity over time.

\subsection{Lexical diversity}

Prefix and particle verbs play an important role in the child's verb lexicon. In the three year observation period we sampled 2890 different main verb lemmas 
(types). 744 verb types are simplex verbs, 335 unseparable prefix verbs, and 1823 are particle verbs. 554 of the particle verbs occur in both separated and unseparated syntactic contexts. In sum, prefix and particle verbs account for $75 \%$ of the child's verb lexicon.

But how productive is the child's early particle verb lexicon? Recall that Figure 3 showed that Leo soon starts to use particle verbs more frequently than his caregivers. Is this due to lexical specificity? It could be that the overuse of particle verbs in the early period is due to the frequent use of just a few verb roots which the child produces with different particles. Such developmental trajectories are proposed by hypotheses which state that children first acquire a syntactic construction with a few prototypical (or pathbreaking) verbs, and take some time to expand their syntactic knowledge to other verbs (e.g., Ninio 1999; Tomasello 2000a). Figure 4 contrasts the frequency of verb roots in particle verbs and in simplex verbs. That is, particle verbs with the same root but different particles were counted as one verb root. In order to check whether there is development towards more lexical diversity, the first and the last six month of the observation period were compared.

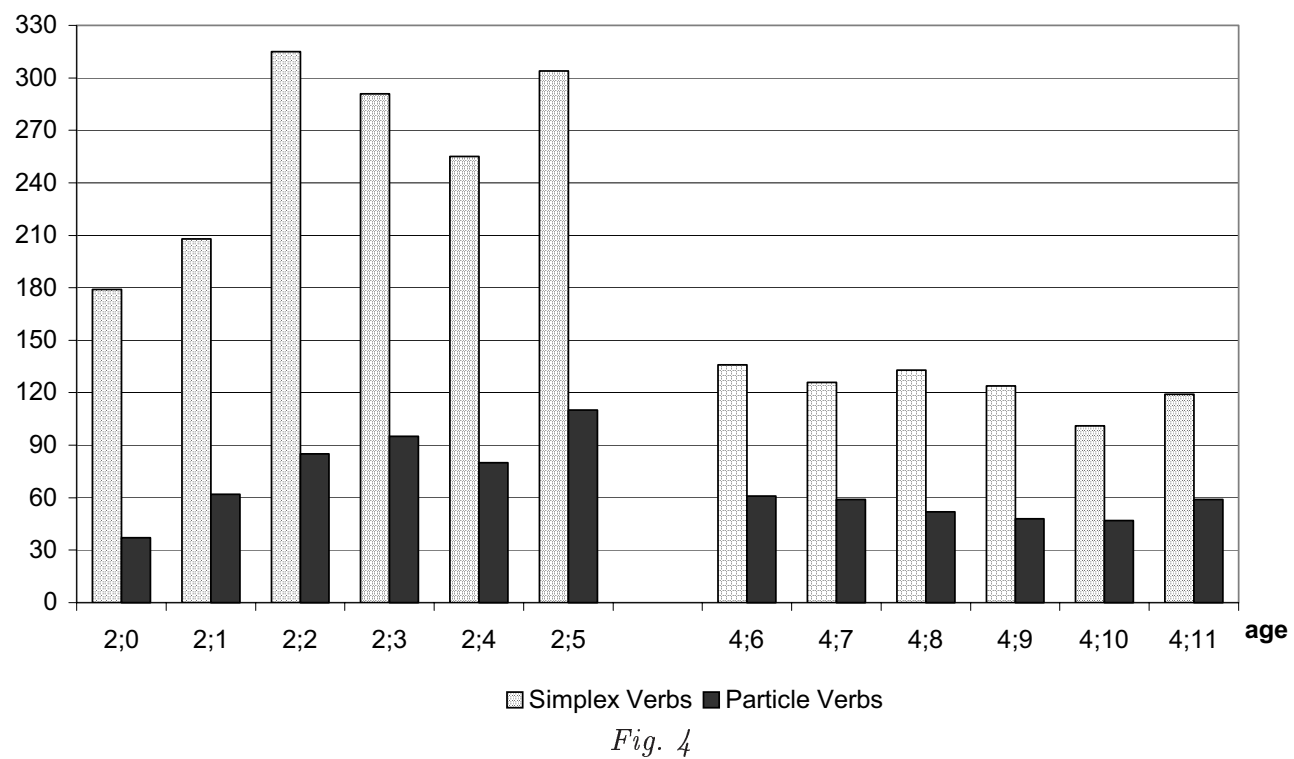

Token frequency of particle and simplex verb roots

Note that Figure 4 depicts absolute type frequencies where the first six months represent data from about 20 one-hour recordings, whereas the last six months 
represent data from only five one-hour recordings. Not surprisingly, the absolute numbers of verb roots increase in the first six months, i.e., the child's verb lexicon increases quickly and stabilizes at 250 to 320 simplex verbs and 80-110 particle verb roots (per 20 recordings). That is, Leo's lexicon is already quite flexible at age 2 . Across development, the relative frequency of particle verb roots increases: at age 2;0, there is one particle verb root per 4.8 simplex verb roots, but there is one particle verb root per 2.8 simplex verb roots at age 2;6. The ratio is between 1:2 and 1:2.6 in the last six months of the observation period (age $4 ; 6-4 ; 11$ ). That is, Leo indeed uses relatively fewer particle verb roots in his very early development. But between 2;3 and $2 ; 5$, when his overuse of particle verbs starts, the lexical diversity of particle roots has also caught up.

However, type frequency could be misleading in the early stages. E.g., 37 different particle verb roots are attested at age 2;0. It is conceivable that only a few of them account for most of the 127 tokens, whereas the majority occurs only once or twice and might be rote-learned. If that was the case, the proportion of the most frequent particle verbs should go down as the child's vocabulary grows. Table 3 depicts the percentage of the five most frequent particle verb roots, and compares Leo's early development between age 2;0 and $2 ; 6$, when he shows a steep increase in the overall proportion of particle verbs (see Figure 3 above), with the last six months of the observation period, when his use of particle verbs corresponds more closely to that of his parents.

Table 3

Percentage of the five most frequent particle verb roots of all particle verb tokens

\begin{tabular}{|l|c|c|c|c|c|c|c|c|c|c|c|c|c|c|}
\hline Age & $\mathbf{2 ; 0}$ & $\mathbf{2 ; 1}$ & $\mathbf{2 ; 2}$ & $\mathbf{2 ; 3}$ & $\mathbf{2} ; \mathbf{4}$ & $\mathbf{2 ; 5}$ & $\mathbf{2} ; \mathbf{6}$ & & $\mathbf{4 ; 6}$ & $\mathbf{4 ;}$ & $\mathbf{4 ; 8}$ & $\mathbf{4 ; 9}$ & $\mathbf{4 ; 1 0}$ & $\mathbf{4 ; 1 1}$ \\
\hline$\%$ & 34 & 42 & 37 & 45 & 50 & 42 & 32 & & 31 & 29 & 36 & 55 & 43 & 37 \\
\hline
\end{tabular}

Although there is an increase in the proportion of the five most frequent verb roots in the first five months, this increase does not account for the overuse of particle verbs in the early stage, nor for the adult-like use in the later stage. In both phases, they account for about one third to one half of Leo's particle verb tokens. While this proportion is relatively high, the five most frequent roots are not always the same roots, but may vary from month to month. The only exception to this is the light verb machen 'to make' which is among the five most frequent verbs all the time, and often is also the most frequent root in absolute terms. However, this does not confirm the hypothesis that there is a small set of general verbs which dominates the category verb. Rather, the data show the child's temporary focus on certain topics and verbs. 


\section{Speed of development and implications for acquisition theory}

The overall impression from the previous sections is that the child gets attuned to the statistical properties of the input language within a few months. This indeed suggests fast and successful acquisition. But how fast is fast? Does this imply that the child is able to abstract German syntax based on a few exemplars? With a database of this size, we can have a closer look at the production rates for both child and adults, in order to get a better estimate of the input the child receives and the amount of work it takes him to reach the adult level. Figures 5 and 6 show the token frequencies for Leo and the adults for the first 45 days of data collection, when Leo was between age $1 ; 11.15$ and $2 ; 0.30$.

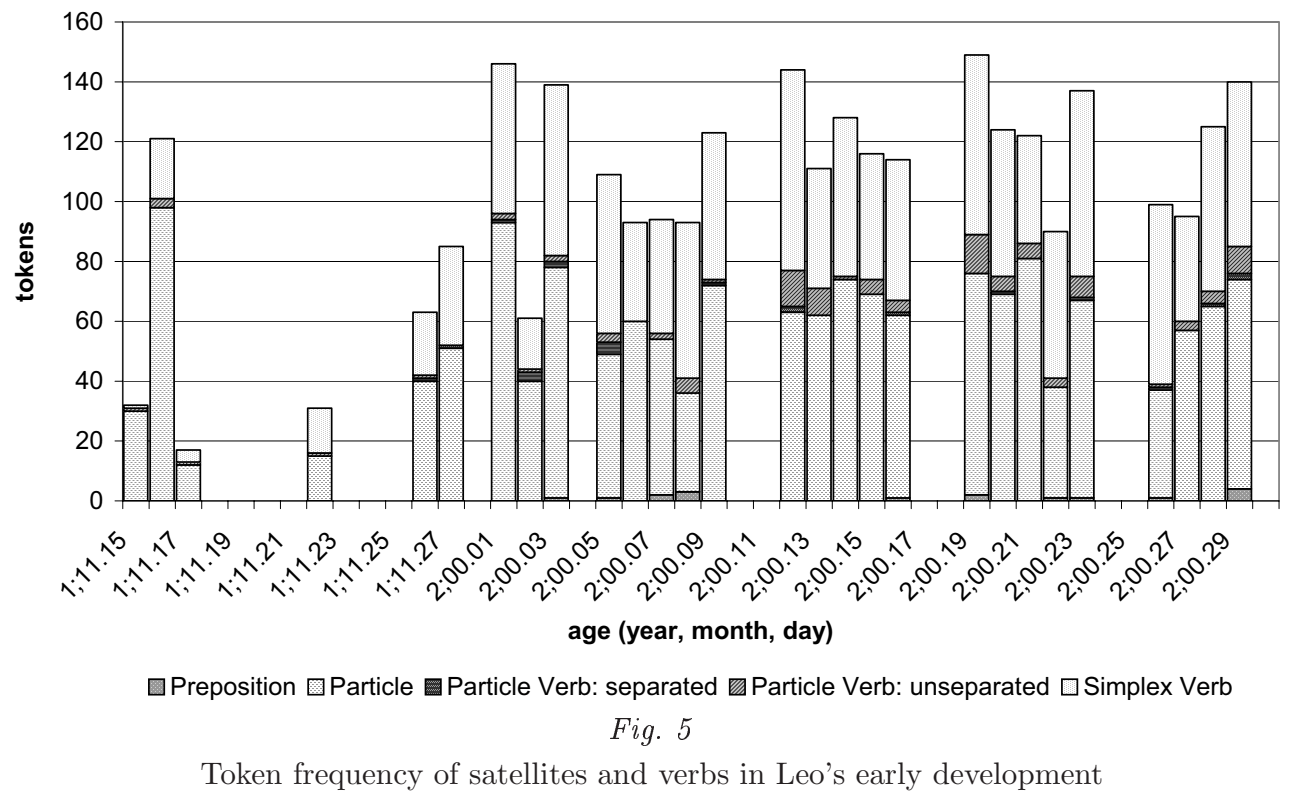

The token frequencies for the individual recordings differ for several reasons. First, some recordings did not last for a whole hour. This is the case for some of the test recordings at $1 ; 11$, but also for some recordings at $2 ; 0$, when the child was simply tired. Second, there is of course no fixed norm about how much talk there is within an hour. The adult data (Figure 6) does not show shifts in proportion, but merely the varying token frequencies from one hour to the next. When we compare the adult structures to the child data from the same recordings, there is a high mismatch. Even in the earliest stage of 


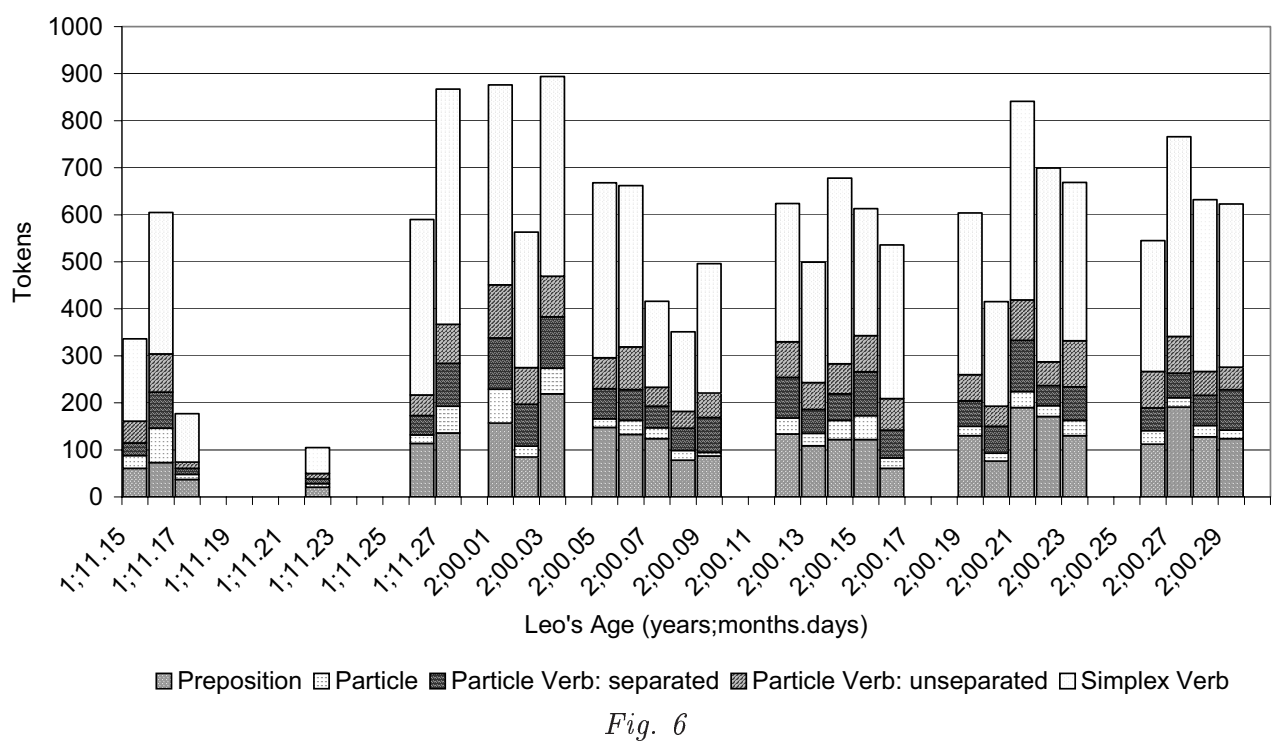

Token frequency of satellites and verbs in Leo's early input

combinatorial speech Leo produces between 60 and 150 satellites and verbs per session (Figure 5). But his system mainly consists of verbal particles and simplex verbs, with a few unseparated particle verbs coming in. The linguistic progress, when looked at from a day-to-day perspective, is rather small. The adults, however, use some isolated particles (Figure 6), but most of their satellites occur in syntactically unambiguous constructions (particle verbs or prepositional phrases).

These data suggest that while Leo has already identified the component parts in the domain of satellites and verbs, he is not yet able to use them in larger constructions. This restriction is mainly due to the general short utterance length at this stage. At age 1;11, Leo was just at the onset of the two-word stage, at the end of age 2;0, three to four-word utterances were in his production range. But while he is producing such short utterances, the adult input he hears acts as a steady role model or 'corrective'. The token frequency the child gets to hear in each hour is quite remarkable: the adults produce between 500 and 900 lexical elements per hour which provide evidence for the grammatical organization and structural preferences of the target language German. 
Figure 5 also allows to draw conclusions about the nature of development regarding the question of whether early, non-adult like constructions just disappear when the child learns the adult way of encoding events, or whether these premature constructions remain to be used in parallel to the more advanced ones. Crucially, the course of development shows that while the proportion between verbal particles and simplex verbs shifts (cf. Figure 3 above), the absolute frequency of verbal particles does not go down. Rather, new acquisitions like simplex and particle verbs come in on top of structures mastered earlier. Thus, the token frequencies show the enormous amount of practice with which early structures are used before new ones come in. And they show that developmental change may not be a matter of re-organization of the system by replacing less advanced structures by more advanced structures, but of adding the more advanced structures on top of the less advanced structures, which still form the backbone of the child's language production. If this interpretation proves to be correct for other structural domains, it follows that the most important aspect of language development is not the emergence of a new structure, but establishing these structures in language production. In the final section I will outline this perspective.

\section{Language acquisition as an automatization process}

Psycholinguistic research on language production and comprehension emphasises the speed and high degree of automatization in language processing (e.g., Levelt 1989). But of course, such skills have to be acquired, i.e., language production has to be routinized. To support this claim, I computed the production rate of the five constructions under investigation. Table 4 presents the average frequencies per hour in the adult data and in Leo's data at the beginning and the end of the observation period.

The adult data show the speed of language production: on average, there are 576 satellite or verb tokens per hour, or one every 6 seconds. Naturally, the two-year old Leo lags behind in production rate: simplex verbs and particles occur on a regular basis, but particle verbs and prepositional phrases are still quite rare. Some three years later (age 4;10 to 4;11) he has mastered all of these structural properties and produces syntactically quite advanced constructions. However, his production rate still is about three to four times lower than that of the adults. These figures suggest that what is different in adult language at this stage of the child's development is the higher degree of fluency or automatization. 
Table 4

Production rates of satellites and verbs: tokens per hour

\begin{tabular}{|l|c|c|c|}
\cline { 2 - 4 } \multicolumn{1}{c|}{} & $\begin{array}{c}\text { Adults } \\
\text { (144 recordings) }\end{array}$ & $\begin{array}{c}\text { Leo, age 2;0 } \\
\text { (22 recordings) }\end{array}$ & $\begin{array}{c}\text { Leo, age 4;10 and 4;11 } \\
\text { (10 recordings })\end{array}$ \\
\hline Simplex Verbs & 337 & 25 & 99 \\
\hline $\begin{array}{l}\text { Unseparated } \\
\text { Particle Verbs }\end{array}$ & 57 & 2 & 23 \\
\hline $\begin{array}{l}\text { Separated } \\
\text { Particle Verbs }\end{array}$ & 52 & 0.5 & 13 \\
\hline Particles & 15 & 40 & 6 \\
\hline $\begin{array}{l}\text { Prepositional } \\
\text { Phrases }\end{array}$ & 115 & 0.7 & 44 \\
\hline
\end{tabular}

\section{Summary and discussion}

The data presented here give a first insight into the actual frequency and the conventionality of particular linguistic structures. It is likely that when speakers talk that fast, there is not much time to weigh one's words like a poet would. Thus, this case study provides support for a view which sees language acquisition as a process of becoming a fluent and proficient speaker, rather than as one of acquiring syntactic competence only. Syntactic competence, i.e., the ability to produce a certain structure productively, is one aspect of the acquisition process, but does not provide the full picture of language development. In particular, the competence view does not account for how and when we choose between the different structural formats provided in each given language. Recall that Dutch and German have almost the same structural properties, but seem to have different preferences as to when to use them (Behrens 1998). Recent acquisition research has emphasized a performance and production oriented perspective for semantic (e.g., Choi-Bowerman 1991; Brown 1998) and syntactic development (e.g., Slobin 1991; 1997b;c).

Slobin's notion of "thinking for speaking" emphasizes the role of conventionality in language use and language learning, since individual languages seem to shape our perception of states and events, as well as our preferences in how to encode them linguistically. The first prerequisite for this ability is to identify the structural properties of the target language. Ragnarsdóttir-Strömqvist (1997) assign such differences to language-specific "packaging and filtering effects". Wijnen et al. (2001) provide a similar account regarding root infinitives in early child language and argue that children do not simply acquire the most frequent structures, but use other information like 
verb placement as well. The data analyzed in this paper confirm such a view by providing information about the input that is available over time. The computations of the speech rate in the input revealed that the child is "swamped" in information about the basic syntactic organization of German. And Leo's course of development shows that his production quickly becomes finely attuned to the distributional properties of the adult language. That is, he adapts his language use to the distributional properties of the language he hears. That children are sensitive to input patterns is also shown in recent experiments which test syntactic priming: children are likely to produce sentence structures they have heard before (Savage et al. 2002).

The second prerequisite for "thinking for speaking" is to find out about the conventional way of encoding events. The input data show that the grammatical properties of the input language remain stable over time. The caregivers did not simplify the language addressed to the small child by avoiding grammatically complex phenomena such as (separated) particle verbs or prepositional phrases. This suggests that particle verbs, which form an obstacle for many second language learners of German, are an unmarked phenomenon for native speakers of German. Slobin (1996) demonstrated that narratives of English- and Spanish-speaking adults differed in the way they depicted events in accordance with the lexicalization patterns of their native language. Such conventions even seem to carry over into second language learning in early adulthood. Laufer-Eliasson (1993) asked speakers from different linguistic backgrounds to judge English sentences which had either a simplex verb or a semantically equivalent particle verb. It turned out that speakers with a satellite-type native language preferred the particle verb variant, whereas speakers with a verb-type native language preferred the simplex verb variant. The data presented here show that the basis for these preferences is laid in very early childhood.

The case study on Leo's language development provides only a first and rather global impression of when he becomes sensitive to the conventions of language use, and of how these conventions might shape his perception of events. But it is by no means clear how this process works exactly. The high input frequency of the structures under investigation give us some idea of the forcefulness of linguistic conventions. Nevertheless, frequency distribution cannot be deterministic. Languages change over time (cf. the synchronic differences between the Germanic languages), and this implies that speakers are able to acquire new linguistic structures and to override their earlier preferences. Second, the differences between closely related languages are rather subtle. On a global level, German, Dutch and English share the distinction 
between prepositional phrases and particle verbs. But in English with its different word order patterns, this distinction is sometimes very hard to draw. German and Dutch are more similar, but not completely identical. They differ, for example, in how particles can be morphologically different from prepositions. German particles often have directional information (compare the preposition auf 'on' with the corresponding particles her-auf or colloquial rauf 'onto'). Dutch particles do not have this property. Instead, word order can encode the difference between directional and locative reading. Future research will have to show which aspects of the input language are responsible for the crosslinguistic differences found in language acquisition, and how the pressure of linguistic conventions relates to the drift of language change.

\section{Acknowledgements}

My interest in this topic started in the "Reference Group" and "Argument Structure Group" at the Max-Planck-Institute for Psycholinguistics. The analyses on the crosslinguistic acquisition of particle verbs in West-Germanic was supported by a research grant from the Deutsche Forschungsgemeinschaft (Be 1513). The high density corpus reported on was collected at the Max-Planck-Institute for Evolutionary Anthropology in Leipzig (Germany). The work for this paper was also carried out at Leipzig, and I wish to thank the Child Language Group for fruitful discussions, as well as Solvejg Kühnert, Jana Jurkat, Susanne Mauritz, Silke Brandt, Eva Lübke, and "The Leos" for their collecting, transcribing and coding the data.

\section{References}

Behrens, Heike 1998. How difficult are complex verbs: evidence from German, English and Dutch. In: Linguistics $36: 679-712$.

Bennis, Hans - Marcel den Dikken - Peter Jordens - Susan Powers - Jürgen Weissenborn 1995. Picking up particles. In: Dawn MacLaughlin-Susan McEwen (eds.) Proceedings of the 19th Annual Boston University Conference on Language Development, 70-81. Cascadilla Press, Somerville MA.

Blom, Corrien - Geert Booij 2003. The diachrony of complex predicates in Dutch: a case study in grammaticalization. In: Acta Linguistica Hungarica 50 :57-87.

Brown, Penelope 1998. Children's first verbs in Tzeltal: evidence from the early verb category. In: Linguistics $36: 713-53$.

Choi, Soonja-Melissa Bowerman 1991. Learning to express motion events in English and Korean: the influence of language-specific lexicalization patterns. In: Cognition 41: 83-121.

Clark, Eve V. 1993. The lexicon in acquisition. Cambridge University Press, Cambridge.

Laufer, Batia - Stig Eliasson 1993. What causes avoidance in L2 learning? L1-L2 difference, L1-L2 similarity or L2 complexity? In: Studies in Second Language Acquisition 15: $35-48$.

Acta Linguistica Hungarica 50, 2003 
Levelt, Willem J.M. 1989. Speaking: From intention to articulation. MIT Press, Cambridge MA.

MacWhinney, Brian 2000. The CHILDES-Project: tools for analyzing talk (Third edition). Erlbaum, Mahwah NJ.

Ninio, Anat 1999. Pathbreaking verbs in syntactic development and the question of prototypical transitivity. In: Journal of Child Language 26:619-53.

Ragnarsdóttir, Hrafnhildur-Sven Strömqvist 1997. The linguistic encoding of spatial relations in Scandinavian child language development. In: Eve Clark (ed.) Proceedings of the 28th Child Language Research Forum, 271-83. CSLI Publications, Stanford CA.

Savage, Ceri-Elena V. M. Lieven - Anna Theakston - Michael Tomasello 2002. Testing the abstractness of children's linguistic representation: lexical and structural priming of syntactic constructions in young children. MPI for Evolutionary Anthropology, Leipzig.

Slobin, Dan I. 1991. Learning to think for speaking: native language, cognition and rhetorical style. In: Pragmatics 1:7-25.

Slobin, Dan I. 1996. Typology and rhetoric: verbs of motion in English and Spanish. In: Masayoshi Shibatani-Sandra A. Thompson (eds.) Grammatical constructions: their form and meaning, 195-219. Oxford University Press, Oxford.

Slobin, Dan I. (ed.) 1997a. The crosslinguistic study of language acquisition. Volume 5: Expanding the contexts. Erlbaum, Mahwah NJ.

Slobin, Dan I. 1997b. The origins of grammaticizable notions: beyond the individual mind. In: Slobin (1997a, 265-323).

Slobin, Dan I. 1997c. The universal, the typological, and the particular in language acquisition. In: Slobin (1997a, 1-39).

Talmy, Leonard 1985. Lexicalization patterns: semantic structures in lexical forms. In: Timothy E. Shopen (ed.) Language typology and syntactic description. Vol. 3: Grammatical categories and the lexicon, 57-149. Cambridge University Press, Cambridge.

Tomasello, Michael 2000a. Do young children have adult syntactic competence? In: Cognition $74: 209-53$.

Tomasello, Michael 2000b. First steps toward a usage-based theory of language acquisition. In: Cognitive Linguistics $11: 61-82$.

Wijnen, Frank - Gerard Bol 1994. The escape from the optional infinitive stage. Manuscript. Rijksuniversiteit Groningen.

Wijnen, Frank - Masja Kempen - Steven Gillis 2001. Root infinitives in early Dutch child language: an effect of input? In: Journal of Child Language 28:629-60.

Address of the author: Heike Behrens

German Department

University of Groningen

P.O. Box 716

9700 AS Groningen

The Netherlands

h.behrens@let.rug.nl 